\title{
Distal and proximal motivational processes related to flow experience: Investigating the role of implicit motives, affective and cognitive preferences, and perceived abilities
}

\author{
Anja Schiepe-Tiska ${ }^{1}$ (D) Kaspar Schattke ${ }^{2} \cdot$ Jörg Seeliger ${ }^{3} \cdot$ Hugo M. Kehr ${ }^{3}$
}

Accepted: 20 January 2021 / Published online: 22 February 2021

(C) The Author(s) 2021

\begin{abstract}
One of the prominent questions in flow research is the investigation of conditions that need to be met so that people will get involved in an activity for the sheer sake of doing it. The present study examined the relationship between distal (i.e., implicit motives) and proximal (i.e., affective preferences, cognitive preferences, perceived abilities) motivational processes and flow experience based on assumptions of the compensatory model of motivation and volition. In order to arouse the implicit agentic motive, 63 participants worked on an online platform in an open innovation environment. Results showed that affective preferences mediated the effect of the implicit agentic motive on flow experience. Moreover, a hierarchical regression analysis with simple slope tests yielded that, at the proximal level, the congruence of affective preferences, cognitive preferences, and perceived abilities was associated with flow experience. The present research adds some new and essential ingredients to Csikszentmihalyis' traditional conception of flow.
\end{abstract}

Keywords Flow experience $\cdot$ Implicit agentic motive $\cdot$ Affective preferences $\cdot$ Cognitive preferences $\cdot$ Perceived abilities

\section{Introduction}

When successful athletes are asked about what they experience during competitions, they often refer to a feeling of "being in the zone". For example, Katie Taylor, four-time World Champion and Olympic Champion in women's boxing, after winning the World Championship in 2012, stated: "I am so focused during competition time that I often do not realize where I am. For me it was just another place and another competition. When I am in the zone, nothing else matters, I

The study has been conducted while all authors were affiliated with the Chair of Psychology, TUM School of Management, Technical University of Munich.

Anja Schiepe-Tiska

schiepe-tiska@tum.de

1 Centre for International Student Assessment (ZIB) e.V., TUM School of Education, Technical University of Munich, Munich, Germany

2 Département de psychologie, Université du Québec à Montréal, Montréal, QC, Canada

3 TUM School of Management, Technical University of Munich, Munich, Germany am purely concentrated on the job at hand." (International Boxing Association, 2012).

Within the research literature, the state of being in the zone is also known as flow experience (Marr, 2001). Flow is a state "in which people are so intensely involved in an activity that nothing else seems to matter; the experience itself is so enjoyable that people will do it even at great cost, for the sheer sake of doing it" (Csikszentmihalyi, 1990, p. 4). Flow is characterized by six components: (a) merging of action and awareness, (b) centering of attention on a limited stimulus field and a high level of concentration, (c) loss of reflective self-consciousness, (d) high sense of control of one's actions and the demands of the environment, (e) experience of coherent and noncontradictory demands for actions and unambiguous feedback, and (f) autotelic nature (Csikszentmihalyi, 1975). The component of autotelic nature reflects a state of intrinsic motivation in the sense that the activity is performed for its own sake without the need for external goals or rewards (Csikszentmihalyi, 1975; Rheinberg \& Engeser, 2018). All components are linked together and depend on each other. Therefore, flow reflects a distinct combination of different experiential states (cf. Schiepe-Tiska \& Engeser, 2017).

Flow is related to improved performance (Engeser \& Rheinberg, 2008; Erhel \& Jamet, 2019; Schüler, 2007), increased creativity (Csikszentmihalyi, 1997), and higher well- 
being (Clarke \& Haworth, 1994; Csikszentmihalyi \& LeFevre, 1989; Ilies et al., 2017; Massimini \& Carli, 1988; Schüler, 2007; Shernoff, Csikszentmihalyi, Schneider, \& Shernoff, 2003). These positive consequences raise the question of what conditions need to be met so that people will get involved in an activity for the sheer sake of doing it. What are factors within a person and/or the situation that facilitate flow experience?

The emergence of flow has been addressed by several approaches. Research in the tradition of Csikszentmihalyi (1975) assumed that flow results when the perceived demands of a situation match the perceived skills of a person (Csikszentmihalyi, 1975), especially in the combination of high skills/high challenge in contrast to low skills/low challenge (Csikszentmihalyi \& Csikszentmihalyi, 1988; Massimini \& Carli, 1988). A range of empirical studies confirmed that individuals experience more flow in optimal balance conditions compared to easy and difficult conditions (e.g., Abuhamdeh \& Csikszentmihalyi, 2009; Engeser \& Rheinberg, 2008; Keller \& Bless, 2008; Keller \& Blomann, 2008). However, they also revealed that a balance does not determine flow per se (Abuhamdeh \& Csikszentmihalyi, 2012; Moneta \& Csikszentmihalyi, 1996), but makes it just more likely (Baumann, 2021; Engeser \& Rheinberg, 2008). Hence, people seem to differ in the amount and quality of flow, as well as in the incentives they perceive in activities that help them to attain flow (Csikszentmihalyi, 1975; Csikszentmihalyi \& Csikszentmihalyi, 1988; Csikszentmihalyi \& LeFevre, 1989; Nakamura \& Csikszentmihalyi, 2002). Although the existence of individual differences was acknowledged early in flow theory by introducing the concept of autotelic personality (Csikszentmihalyi, 1975), researchers have only recently started to empirically examine the relation between personality facets and flow by considering possible moderators of the effect of the demand-skill balance.

For example, Keller and Bless (2008) showed that actionoriented persons, who stay immersed in an ongoing task with high concentration experienced more flow when the demands of the game were adapted to their abilities than state-oriented persons, who become easily distracted from a task and work on other things in between. Keller and Blomann (2008) added that people with a strong internal locus of control (i.e., the belief that outcomes depend on the work and effort a person puts into a task; Rotter, 1966) were more likely to enter the flow state as compared to people with a weak internal locus of control. Other researchers focused on the implicit achievement motive - the desire to surpass personal standards of excellence (McClelland, Atkinson, Clark, \& Lowell, 1953) - and demonstrated that it moderates the relation between demand-skill balance and flow (Baumann \& Scheffer, 2010, 2011; Engeser \& Rheinberg, 2008; Schattke, Brandstätter, Taylor, \& Kehr, 2015; Schüler, 2007).
The Compensatory Model of Motivation and Volition

A model that broadens the scope of explaining how flow emerges by integrating research based on the demand-skill balance and research based on implicit motives is the compensatory model of motivation and volition (Kehr, 2004b, 2020). This model is based on the assumption of distal levels of motivational processes that are related to proximal levels (cf. Kanfer \& Heggestad, 1997). It states that the arousal of implicit motives at the distal level would lead to implicit behavioral tendencies (i.e., affective preferences) at the proximal level.

Implicit motives are unconscious motivational needs that orient attention, and select and energize behavior towards specific classes of rewarding task-intrinsic incentives (McClelland, 1987). They can be classified according to different motive themes. Bakan (1966) distinguished two fundamental modalities of human existence: agentic and communal motives. The agentic motive focuses on the individual self and subsumes self-oriented needs such as achievement and power. It characterizes a need for mastery-experiences, autonomy, instrumentality, and dominance. Hence, it includes aspects of the achievement motive that is also geared toward rewarding mastery experiences (Schultheiss \& Brunstein, 2005), but broadens the scope by additionally including aspects of the power motive, which is the need for having impact on others (Winter, 1973). By contrast, the communal motive focuses on others and refers to the need for relationships, interdependence, and connection. Implicit motives are built on associative networks that link situational cues with basic affective experiences (McClelland, 1985).

Implicit behavioral tendencies at the proximal level are expressed as affective preferences. Affective preferences indicate whether the current task is pleasant for the person (Kehr, 2004b, 2020). In line with McClelland (1985), Kehr proposed that the arousal of implicit motives by a certain task will lead to affective preferences for that task. Therefore, affective preferences should mediate the relation between aroused implicit motives and flow. However, to date, no studies have examined the mediating role of proximal components.

At the proximal level, affective preferences resulting from aroused implicit motives do not affect flow in isolation. They need to interact with cognitive preferences and perceived abilities in order to foster flow. According to the compensatory model, flow emerges when a person experiences high levels of affective preferences, cognitive preferences, and perceived abilities while conducting a specific task (Kehr, 2004b, 2020).

Cognitive preferences indicate whether the current task is important to the person. High cognitive preferences for a task will ensure that a person will limit his or her stimulus field in order to concentrate on the task. By doing so, no other task will be able to distract the attention of the person from the task. Hence, affective and cognitive preferences need to be in line with each other. This would either be the case when a person 
enjoys the current task and it is additionally important to her, or the task is enjoyable and no other tasks are more important at the present moment. When there is an incongruence, constant volitional regulation is needed to either enhance cognitive preferences for the current task or suppress unwanted affective preferences, which would be incompatible with flow (Kehr, 2004b, 2020). Engeser and Rheinberg (2008) already revealed that high cognitive preferences moderated the relation between the demand-skill balance and flow. For highly important tasks, flow was still high when the perceived demands were low. For less important tasks, flow was high only when people perceived a demand-skill balance. Although Engeser and Rheinberg (2008) also found a moderation effect for the implicit achievement motive, they did not examine a joint effect of cognitive preferences and the achievement motive.

Perceived skills are conceptualized as people's perception of the amount of control they can exert over the current situation (Kehr, 2004b). They are mostly determined by past performance (Bandura, 1977; Carver \& Scheier, 1982; Kanfer \& Ackerman, 1989). When individuals perform a task successfully, they feel confident about being successful again on similar tasks (Bandura, 1977). Moreover, they perceive the performance of similar tasks as easier (Ajzen, 1991). As a result of the repeated experiences, individuals develop automatic behavioral control programs. These programs are called scripts (Lord \& Kernan, 1987; Schank \& Abelson, 1977) and they guide routine behaviors. According to the compensatory model, perceived skills themselves have no relevance for motivated behavior; they need to interact with affective and cognitive preferences in order to influence behavior (Kehr, 2004b). Similar to Csikszentmihalyi (1990), Kehr (2004b) assumes that low perceived abilities preclude flow. They are associated with a low degree of automation and frequent script interruptions that counteract the experience of flow. In contrast to Csikszentmihalyi (1990), Kehr's model proposes that when perceived abilities exceed task demands flow is not necessarily impeded. Only when low demands prevent the arousal of flow-concordant implicit motives and thus, lead to low affective preferences, flow will be hindered. At the same time, if low demands activate conflicting cognitive preferences, flow will be hindered as well. Hence, the compensatory model leads to the assertion that cognitive preferences and perceived abilities moderate the effect of affective preferences on flow. High levels of affective preferences, cognitive preferences, and perceived abilities would lead to the highest level of flow and any missing piece would decrease the experience of flow. In particular, an incongruence between affective and cognitive preferences should lower a persons' flow experience. Consequently, low levels of affective preferences, cognitive preferences, and perceived abilities would lead to the lowest level of flow. However, a comprehensive consideration of all proximal components for the experience of flow has not been examined yet.

\section{Present Research}

The present study was designed as a pilot study to test central assumptions of the compensatory model of motivation and volition (Kehr, 2004b, 2020). We conducted the study in an open innovation environment using an online platform, that had been developed in the context of the project this study was part of. Open innovation is characterized as a self-organized, self-motivated, and collaborative development and creation of new and innovative ideas and products (von Hippel, 2005). Open innovation projects have attracted a lot of attention of motivation researchers (e.g., Lakhani \& von Hippel, 2003; Roberts, Hann, \& Slaughter, 2006; Schroer \& Hertel, 2009) who intend to find answers to an obvious question: What motivates people to engage in open innovation? It has been shown that people participate in open innovation online platforms because of different incentives such as solving a certain problem, improving existing software, enhancing their reputations, or dominating other developers (e.g., Lakhani \& von Hippel, 2003; Schroer \& Hertel, 2009).

As deduced from these findings, it seems likely that these incentives arouse the implicit agentic motive, which is defined as a need for autonomy, instrumentality, and dominance (Bakan, 1966). Agency-oriented people are primarily concerned with self-mastery, status, achievement, and empowerment. In line with research on the implicit achievement motive (Baumann \& Scheffer, 2010, 2011; Engeser \& Rheinberg, 2008; Schattke, Brandstätter, Taylor, \& Kehr, 2014; Schüler, 2007), the present study first examined whether the implicit agentic motive is positively associated with flow.

\section{Hypothesis 1 The higher the implicit agentic motive, the more flow is experienced.}

Building on the work of McClelland (1985), who stated that implicit motives are built on associations with innately triggered affective experiences, Kehr (2004b) proposed that the arousal of implicit motives by a certain task at the distal level leads to affective preferences for that task at the proximal level. According to the compensatory model (Kehr, 2004b), affective preferences for a task stemming from aroused implicit motives will lead to the experience of flow. Therefore, it seemed likely that affective preferences would mediate the relation between the aroused agentic motive and flow (mediation hypothesis).

\section{Hypothesis 2 The relation between the implicit agentic mo- tive and flow is mediated by affective preferences.}

However, affective preferences interact with cognitive preferences and perceived abilities in order to determine flow (Kehr, 2004b). Therefore, high affective preferences, high cognitive preferences, and high perceived abilities should lead to the 
highest level of flow compared to low affective preferences, low cognitive preferences, and low perceived abilities, which should lead to the lowest level of flow (moderation hypothesis). Any missing piece should decrease the experience of flow - particularly when there is an incongruence between affective and cognitive preferences (Kehr, 2004b, 2020; Schiepe-Tiska \& Engeser, 2021).

Hypothesis 3 The relation between affective preferences and flow is moderated by cognitive preferences and perceived abilities. Specifically, individuals high in affective preferences, cognitive preferences, and perceived abilities experience more flow as compared to individuals high in cognitive preferences and perceived abilities but low in affective preferences. In addition, individuals low in affective preferences, cognitive preferences, and perceived abilities experience less flow as compared to individuals low in cognitive preferences and perceived abilities but high in affective preferences. Moreover, people with an incongruence between affective and cognitive preferences experience lower levels of flow as compared to people with congruent high levels of affective and cognitive preferences, but higher levels of flow as compared to individuals with congruent low levels of affective and cognitive preferences.

\section{Method}

\section{Participants}

Sixty-three students (49 men and 14 women), who were enrolled as undergraduate and graduate students in computer science participated in this study and received course credit for their participation. On average, they were 21.73 years old $(S D=2.44$; one student did not state his or her age).

\section{Procedure}

Before coming to the lab, the agentic motive of the participants was assessed online. Upon arrival at the lab, participants were seated randomly at individual computer stations. Participants saw a virtual online platform on their monitor (IdeaStream; Forster, 2010). This platform was designed in a way that participants could create new and innovative ideas in virtual teams. Groups of two to four participants worked collaboratively on the virtual online platform at a time. Group size, age, and gender did not affect the results of the study and were therefore disregarded in subsequent analyses.

Participants were asked to create new and innovative ideas concerning the question "What possibilities can you think of to employ student's tuition fees in a useful way?" Whenever a participant wrote an idea on the platform, other participants in the group could read the idea on their own computer. Some features of the platform were deliberately designed to arouse the agentic motive (e.g., high score list of the number of ideas, notepad to allow participants to develop their ideas first before sharing; see Schattke \& Kehr, 2009). Prior to the actual study, participants were introduced to the features of the platform. In the first creativity session, participants worked for $5 \mathrm{~min}$ to create as many ideas as possible in an online brainstorming session. Then, students' affective preferences, cognitive preferences, and perceived abilities were assessed while working on the platform. A second 5 min creativity session followed. At the end of this session, each participant's flow experience was assessed. Finally, participants were fully debriefed and thanked for their participation. The study lasted approximately $30 \mathrm{~min}$.

\section{Materials}

Agentic Motive The two subscales hope of control and hope of success from the Multi-Motive-Grid (MMG, Sokolowski, Schmalt, Langens, \& Puca, 2000) were used to assess the agentic motive. The MMG is a semi-projective instrument that contains 14 pictures, showing ambiguous everyday situations. These pictures shall arouse the implicit agentic motive. They are followed by a series of verbal statements that describe typical motive relevant emotions, cognitions, goal anticipations, and instrumental actions. People indicate whether these descriptions describe the way they would think or feel in the situation shown in the picture (e.g., "Trying to influence other people", "Feeling confident about succeeding on this task"; Cronbach's $\alpha=.62$ ). Therefore, they project the statements onto the ambiguous pictures. Several studies provided support that the MMG is a reliable and valid instrument for the assessment of implicit motives (e.g., Gable, Reis, \& Elliot, 2003; Kehr, 2004a; Langens \& Schmalt, 2002; Schattke et al., 2014; Schüler, 2010; Thielgen, Krumm, Rauschenbach, \& Hertel, 2015).

The implicit agentic motive was calculated by summing the standardized power motive score and the standardized achievement motive score from the MMG and dividing by 2 (e.g., Brunstein, Schultheiss, \& Grässmann, 1998). This approach is in line with findings of factor analyses computed by Sokolowski et al. (2000). These results showed that the MMG scales hope of control and hope of success can form a combined factor. Due to a technical error, one item of the subscale hope of control was missing (Picture 7, Item 8).

Affective Preferences, Cognitive Preferences, and Perceived Abilities The three components were assessed with the three- 
component scale (see Appendix), which was adapted for working with the platform. Each scale consisted of four items. Participants could rate each item on a 7-point scale from 1 (not at all) to 7 (very much). Cronbach's $\alpha$ for affective preferences was $\alpha=.85$; for cognitive preferences: $\alpha=.77$; and for perceived abilities: $\alpha=.68$.

Flow Experience Flow was assessed with the Flow Short Scale (FKS; Engeser \& Rheinberg, 2008). This scale measures all components of flow with 10 items (e.g., "I am completely absorbed in what I am doing"; Cronbach's $\alpha=.76$ ) that are endorsed on a 7point scale ranging from 1 (not at all) to 4 (partly) to 7 (very much).

\section{Results}

The analyses were conducted with SPSS 21 and involved correlation analysis, hierarchical regression analysis, and mediation analysis. For the mediation analysis the SPSS macro PROCESS (Hayes, 2013) was used, which tests the direct, indirect, and total effects based on bias-corrected confidence intervals. Descriptive statistics are given as $M$ and $S D$ unless otherwise indicated. All tests were two tailed, and an alpha level of .05 was employed in all analyses.

\section{Preliminary Analyses}

Descriptive statistics and correlations of all variables are presented in Table 1. Although the components affective preferences, cognitive preferences, and perceived abilities of the threecomponent scale were only correlated on a medium level, we tested for any subtle forms of multicollinearity. The variance inflation factor was $<1.94$, which is well below the value of 10 that is seen as problematic (Bowerman \& O'Connell, 1990; Myers, 1990).

All scores were standardized for further analyses. Further preliminary analyses indicated that neither age nor gender had significant effects on the results reported below.

\section{Regression and Mediation Analyses}

First, we tested whether the agentic motive predicted flow (Hypothesis 1). The regression analysis yielded only a marginally significant effect of the agentic motive on flow, $b=.20$, $S E=.10, t(61)=1.96, p=.055,95 \% \mathrm{Cl}[-.004, .39], R^{2}=.06$. People high in implicit agentic motivation did not per se experience higher levels of flow while working on the platform as compared to people low in implicit agentic motivation.

In order to test whether the relation between the implicit agentic motive and flow was mediated by affective preferences (Hypothesis 2), the SPSS macro PROCESS (Hayes, 2013) was used that applies bootstrapping procedures. For this analysis, no assumptions about the sampling distribution of the variables are required and it can be applied more confidently to smaller samples (Hayes, 2009; Preacher \& Hayes, 2008). Moreover, this procedure has the highest power to detect indirect effects and the best Type I error control compared to the classical causal step approach (Baron \& Kenny, 1986) and the Sobel test (Hayes, 2009). The procedure bootstraps the sampling distribution of the path $a b$ (i.e., the indirect path from the predictor to the dependent variable via the mediator) and derives a confidence interval for the bootstrapped sampling distribution. The results of the bootstrap procedure with 10,000 bootstrap samples revealed a significant positive indirect effect of the agentic motive on flow through affective preferences; point estimate $.14, S E=.07,95 \%$ $\mathrm{Cl}[.02, .30]$. Thus, the level of affective preferences for the task mediated the effect of the agentic motive on flow while working on the platform. The higher the agentic motive, the higher the affective preferences, and the more flow was reported.

\section{Moderation Analysis}

Next, the interaction hypothesis, that affective preferences, $\operatorname{cog}$ nitive preferences, and perceived abilities interact in order to affect flow (Hypothesis 3), was analyzed. In order to test this hypothesis, a hierarchical regression analysis was computed followed by simple slope and slope difference tests (Dawson, 2014). In the first step, flow was regressed on affective preferences, cognitive preferences, and perceived abilities. In the second step, flow was additionally regressed on all two-way
Table 1 Descriptive statistics and correlations

\begin{tabular}{lllllllll}
\hline Variable & $(1)$ & $(2)$ & $(3)$ & $(4)$ & $M$ & $S D$ & Min & Max \\
\hline (1) nAgent & - & & & & 6.71 & 2.07 & 3.00 & 11.00 \\
(2) Affective preferences & $.32 * *$ & - & & & 4.89 & 1.15 & 1.75 & 7.00 \\
(3) Cognitive preferences & $.38^{* *}$ & $.48^{* *}$ & - & & 4.26 & 1.20 & 1.25 & 6.75 \\
(4) Perceived abilities & .24 & $.53^{* *}$ & $.34 * *$ & - & 5.50 & 0.84 & 3.50 & 7.00 \\
(5) Flow & $.24 *$ & $.54^{* *}$ & $.47^{* *}$ & $.56^{* *}$ & 4.75 & 0.81 & 2.70 & 6.40 \\
\hline
\end{tabular}

Note. $N=63$. nAgent $=$ implicit agentic motive. $* p<.05 . * * p<.01$ 
interactions. In the third and final step, flow was additionally regressed on the three-way interaction. The results are presented in Table 2.

In the final step, the hierarchical regression analysis $\left(R^{2}=.54\right)$ yielded a significant three-way interaction of affective preferences, cognitive preferences, and perceived abilities on flow, $b=.21, S E=.08, t(55)=2.65, p=.01,95 \% \mathrm{Cl}[.05, .37]$. The three-way interaction term produced a significant $(p=.01)$ additional increase in $R^{2}\left(\Delta R^{2}=.06\right)$. Therefore, cognitive preferences and perceived abilities significantly moderated the relation between affective preferences and flow while participants worked on the platform (Fig. 1).

To explore whether affective preferences were more strongly related to flow for students additionally high in cognitive preferences and perceived abilities as compared to those low in cognitive preferences and perceived abilities (Lines 1 and 3), simple slope tests at values of one standard deviation above and below the means of cognitive preferences and perceived abilities, depending on affective preferences, were applied (Aiken \& West, 1991; Cohen, Cohen, West, \& Aiken, 2003; Dawson, 2014).

Affective preferences positively predicted flow for individuals high in cognitive preferences and perceived abilities, $b=.35, t(55)=2.56, p=.01$ (Line 1). People high in affective preferences, cognitive preferences, and perceived abilities experienced high levels of flow, while people high in cognitive preferences and perceived abilities but low in affective preferences reported only medium levels of flow. Likewise, affective preferences positively predicted flow for participants low in cognitive preferences and perceived abilities, $b=.59, t(55)=2.00$, $p=.05$ (Line 3). Participants low in affective preferences, cognitive preferences, and perceived abilities experienced lower levels of flow compared to participants low in cognitive preferences and perceived abilities but high in affective preferences, who experienced medium levels of flow.
To further explore the interaction, simple slope differences following the procedure introduced by Dawson and Richter (2006) were analyzed. Results showed that in the prediction of flow by affective preferences, the slope for participants high in cognitive preferences and perceived abilities (Line 1) differed significantly from the slope for participants low in cognitive preferences but high in perceived abilities (Line 4), $t(55)=$ $2.52, p=.01$. Individuals low in affective and cognitive preferences but high in perceived abilities experienced more flow than individuals low in affective preferences but high in cognitive preferences and perceived abilities. Conversely, individuals high in affective preferences, cognitive preferences, and perceived abilities experienced more flow as compared to individuals high in affective preferences and perceived abilities but low in cognitive preferences.

Furthermore, the slope for participants low in cognitive preferences and perceived abilities (Line 3) differed significantly from the slope for participants low in cognitive preferences but high in perceived abilities (Line 4), $t(55)=-2.35, p=.02$. Students low in affective and cognitive preferences experienced flow only when they perceived their abilities to be high compared to low perceived abilities. For individuals high in affective but low in cognitive preferences, it made no difference whether they experienced their abilities as high or low. Both groups experienced flow at a medium level. All other slope differences were not significant.

\section{Discussion}

This pilot study was designed to examine the relationship between distal and proximal motivational processes and flow experience. Based on assumptions of the compensatory model of motivation and volition (Kehr, 2004b, 2020), we tested whether, (a) an aroused agentic motive was associated with
Table 2 Hierarchical regression analysis predicting flow from affective preferences, cognitive preferences, and perceived abilities

\begin{tabular}{|c|c|c|c|c|c|c|}
\hline \multirow[t]{3}{*}{ Predictor } & \multicolumn{6}{|c|}{ Flow experience } \\
\hline & \multicolumn{2}{|l|}{ Step 1} & \multicolumn{2}{|c|}{ Step 2} & \multicolumn{2}{|c|}{ Step 3} \\
\hline & $b$ & $S E$ & $b$ & $S E$ & $b$ & $S E$ \\
\hline Affective preferences & .19 & .10 & .19 & .10 & .17 & .10 \\
\hline Cognitive preferences & $.19 *$ & .09 & $.23 *$ & .09 & .17 & .09 \\
\hline Perceived abilities & $.28 * *$ & .09 & $.25 *$ & .09 & $.19^{*}$ & .09 \\
\hline Affective preferences $*$ cognitive preferences & & & .13 & .09 & .04 & .09 \\
\hline Affective preferences*perceived abilities & & & -.11 & .08 & -.13 & .08 \\
\hline Cognitive preferences*perceived abilities & & & -.05 & .09 & -.10 & .09 \\
\hline Affective preferences*cognitive preferences*perceived abilities & & & & & $.36^{*}$ & .08 \\
\hline Total $R^{2}$ & .44 & & .48 & & .54 & \\
\hline$\Delta R^{2}$ & $.44 * * *$ & & .04 & & $.06^{*}$ & \\
\hline
\end{tabular}

Note. $N=63 . b=$ unstandardized regression coefficient. ${ }^{*} p<.05 . * * p<.01 . * * * p<.001$ 
Fig. 1 Predicted values for flow as a function of affective preferences, cognitive preferences, perceived abilities

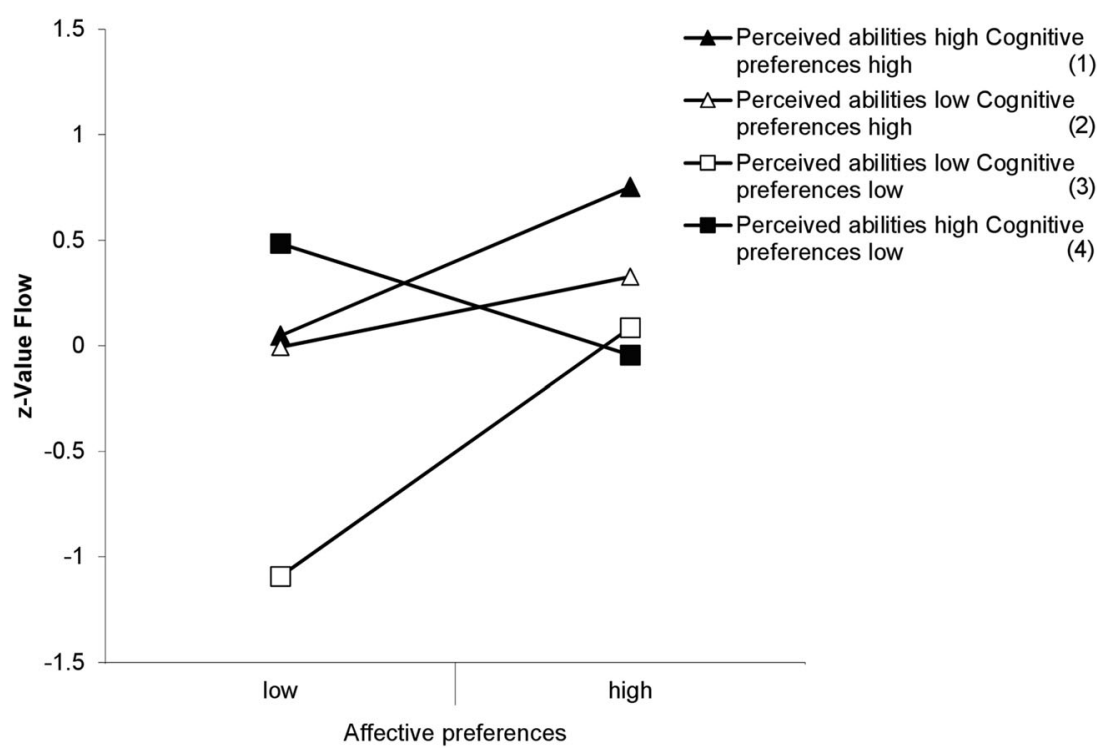

flow, (b) the relation between the agentic motive and flow was mediated by affective preferences, and (c) affective preferences, cognitive preferences, and perceived abilities interacted with each other in order to predict flow.

Our results revealed that a high agentic motive was only marginally related to higher levels of flow. Other studies found a much stronger positive effect of an aroused implicit achievement motive on flow experience (e.g., Baumann \& Scheffer, 2010, 2011; Engeser \& Rheinberg, 2008; Schattke et al., 2015; Schüler, 2007). This may be because the agentic motive, which we aimed to arouse by the platform in this study, additionally includes aspects of the power motive (Bakan, 1966). On one hand, this may be seen as a limitation of the present study as it mixes effects of the achievement and the power motive. However, on the other hand, given that most previous research was conducted in the achievement domain only, this is also an asset of our study. It shows that flow is not confined to the achievement domain but may also occur in other domains (cf. Schiepe-Tiska \& Engeser, 2021). Future studies may also examine whether the arousal of communal motives, which focus more on the relationship with others (Bakan, 1966), are associated with flow experience.

Our second hypothesis, the relation between the implicit agentic motive and flow is mediated by affective preferences, could be confirmed. An aroused implicit agentic motive at the distal level was related to affective preferences at the proximal level, which in turn was associated with flow while working on the platform. Therefore, flow seems to not only be a function of a demands-skill balance as proposed by traditional flow models (Csikszentmihalyi, 1975; Massimini \& Carli, 1988), but the affective character of the task is central for the experience of flow, too, as it indicates the arousal of implicit motives. Hence, this positive affective character needs to be distinguished from the experience of flow itself. Flow is not defined through an affective component (cf. Schiepe-Tiska \& Engeser, 2017), although some conceptualizations and studies confound this affective character with the component of autotelic nature (e.g., Bakker, 2008). However, intrinsically rewarding refers to doing the task for its own sake without the need for external goals or rewards (cf. Rheinberg \& Engeser, 2018 for different conceptualizations of intrinsic motivation). In line with that, Aellig (2004, as cited in Rheinberg \& Engeser, 2018) found that climbers reported not only levels of positive activation (i.e., energetic arousal) but also medium levels of negative activation (i.e., tense arousal) while climbing. A feeling of happiness (i.e., positive valence) was only associated with flow after finishing climbing. Hence, our results may help to better clarify the relationship between flow and positive affect by embedding it in a broader view of aroused implicit motives (cf. Schiepe-Tiska \& Engeser, 2021).

The presented results also confirmed the moderation hypothesis by revealing that, at the proximal level, the congruence of affective preferences, cognitive preferences, and perceived abilities was associated with flow. People low in affective preferences, cognitive preferences, and perceived abilities experienced the lowest level of flow while working on an open innovation platform. By contrast, people high in affective preferences, cognitive preferences, and perceived abilities experienced the highest level of flow. People with incongruent affective and cognitive preferences reported medium levels of flow regardless of their level of perceived abilities. They at least seemed to enter a state of "shallow flow" but maybe not a "deep flow" state, which differ in the level of the feeling of isolation from the environment (Moneta, 2012). However, unexpectedly, people high in perceived abilities but low in affective and cognitive preferences also reported levels of flow higher than the mean. This result is inconsistent with the propositions of the compensatory model. An explanation may be that these people have achieved high levels of flow because they experienced a demand-skill balance as proposed by traditional flow models (Csikszentmihalyi, 1975; Massimini \& Carli, 1988). Another possible explanation is that 
this line reflects both boredom (i.e., low affective preferences) and relaxation (i.e., high affective preferences), which result when skills are greater than demands require. People who feel bored may still exert the concentration necessary to achieve high flow scores, but they are not enjoying themselves very much as the outcome is not important to them (i.e., low cognitive preferences). People, who are relaxed may still enjoy working on the platform, but as the outcome is not as important to them, they experience lower levels of flow. However, we did not assess the perceived demands of the task in this study and thus, future studies are needed to clarify this relationship.

As the study was designed as a pilot study, one limitation is its sample size. As the confidence intervals indicate, the effects were significant even with the small sample size but still close to zero. Hence, the results would need to be replicated using a larger sample. Moreover, this would make a joint test of the mediation and moderation hypotheses possible.

Another limitation is that we used the MMG to assess the implicit agentic motive. The MMG combines features of traditional projective measures (e.g., Picture Story Exercise, Pang, 2010) and questionnaire measures of motives. It is a reliable and valid economic semi-projective instrument for the assessment of implicit motives (cf., Sokolowski et al., 2000). However, Schüler, Brandstätter, Wegner, and Baumann (2015) found that its correlation with traditional projective measures is rather low. They speculate that this may be because these measures cover different aspects of aroused implicit motives. As more research is needed to further explore differences in implicit motive assessment - also in relationship to flow experience - the results should be replicated and thus reinforced by using traditional projective measures.

From a practical perspective, the results of this study show that in an open innovation context as well as on the job and in leisure time in general, it seems valuable to establish a fit between a person's motives and the executing tasks or activities in order to arouse affective and cognitive preferences and to elicit flow. It has already been shown that flow increases a person's performance (e.g., Engeser \& Rheinberg, 2008). Hence, people might be able to exceed their daily performance when they experience flow. However, flow may not only have positive associations. Csikszentmihalyi (1990) himself assumed that, "flow experience, like everything else, is not good in an absolute sense" (p. 70). In line with that, Schüler and Nakamura (2013) showed that flow can be related to risk awareness and risky behavior. Therefore, it seems possible that flow has also the potential to lead to other negative consequences such as tunnel vision or addiction. Hence, additional studies are needed to explore under which circumstances flow entails positive or negative consequences.

In sum, the present research showed that implicit motives, which are aroused by the task at hand, are associated with affective preferences which then interact with cognitive preferences and perceived abilities to determine flow. Our results broaden the scope of flow research in addressing the interplay of distal and proximal processes related to flow experience. Hence, the present research adds some new and essential ingredients to Csikszentmihalyi's (1975) original conception of flow.

Acknowledgments The authors gratefully acknowledge the support of TUM Graduate School's Faculty Graduate Centre TUM School of Management at the Technical University of Munich, Germany.

Funding This study was funded by the German Federal Ministry of Education and Research (BMBF) and the European Social Fund (ESF) [Grant number 01FM07054].

Data Availability The datasets generated and analyzed during the current study are available from the corresponding author on reasonable request.

\section{Declarations}

Ethics Approval The study was conducted according to the Ethical Principles of Psychologists and Code of Conduct of the American Psychological Association from 2019. An ethics approval was not required by institutional guidelines or national regulations, in line with the guidelines of the "German Research Foundation" as the used data was anonymized and no disclosure outside the research is possible.

Informed Consent Participants gave prior written consent.

Conflict of Interest The present study was part of the doctoral dissertation of the first author. On behalf of all authors, the corresponding author states that there is no conflict of interest.

\section{Appendix}

1. Compared to other activities, I like working with the platform. (ap)

2. I want to solve my tasks with the platform as good as possible. (cp)

3. The tasks with the platform I usually handle well. (pa)

4. I feel like working with the platform. (ap)

5. If I want, I can achieve good results while working with the platform. (pa)

6. I want to work with the platform intensely. (cp)

7. Although working with the platform is difficult at times, I enjoy working with it. (ap)

8. It is important to solve my tasks with the platform. (cp)

9. I think I will achieve good results while working with the platform. (pa).

10. Working with the platform is fun. (ap)

11. I have the necessary abilities to handle the tasks with the platform well. (pa)

12. It is important to me to achieve good results while working with the platform. (cp)

ap $=$ affective preferences.

$\mathrm{cp}=$ cognitive preferences

$\mathrm{pa}=$ perceived abilities. 
Open Access This article is licensed under a Creative Commons Attribution 4.0 International License, which permits use, sharing, adaptation, distribution and reproduction in any medium or format, as long as you give appropriate credit to the original author(s) and the source, provide a link to the Creative Commons licence, and indicate if changes were made. The images or other third party material in this article are included in the article's Creative Commons licence, unless indicated otherwise in a credit line to the material. If material is not included in the article's Creative Commons licence and your intended use is not permitted by statutory regulation or exceeds the permitted use, you will need to obtain permission directly from the copyright holder. To view a copy of this licence, visit http://creativecommons.org/licenses/by/4.0/.

\section{References}

Abuhamdeh, S., \& Csikszentmihalyi, M. (2009). Intrinsic and extrinsic motivational orientations in the competitive context: An examination of person-situation interactions. Journal of Personality, 77(5), 1615-1635. https://doi.org/10.1111/j.1467-6494.2009.00594.x .

Abuhamdeh, S., \& Csikszentmihalyi, M. (2012). The importance of challenge for the enjoyment of intrinsically motivated, goal-directed activities. Personality and Social Psychology Bulletin, 38(3), 317330. https://doi.org/10.1177/0146167211427147 .

Aellig, S. (2004). Über den Sinn des Unsinns: Flow-Erleben und Wohlbefinden als Anreize für autotelische Tätigkeiten : Eine Untersuchung mit der Experience Sampling Method (ESM) am Beispiel des Felsklettern [On the sense of nonsense. Flow experiences and well-being as incentives of autotelic activities]. Münster: Waxmann.

Aiken, L, S., \& West, S, G. (1991). Multiple regression: Testing and interpreting interactions. Newbury Park Cal.: Sage.

Ajzen, I. (1991). The theory of planned behavior. Organizational Behavior and Human Decision Processes, 50(2), 179-211. https:// doi.org/10.1016/0749-5978(91)90020-T .

Bakan, D. (1966). The duality of human existence: Isolation and communion in Western man. Boston MA: Beacon Press.

Bakker, A. B. (2008). The work-related flow inventory: Construction and initial validation of the WOLF. Journal of Vocational Behavior, 72(1), 400-414. https://doi.org/10.1016/j.jvb.2007.11.007.

Bandura, A. (1977). Self-efficacy: Toward a unifying theory of behavioral change. Psychological Review, 84(2), 191-215. https://doi.org/ 10.1037/0033-295X.84.2.191 .

Baron, R. M., \& Kenny, D. A. (1986). The moderator-mediator variable distinction in social psychological research: Conceptual, strategic, and statistical considerations. Journal of Personality and Social Psychology, 51(6), 1173-1182. https://doi.org/10.1037/0022-3514.51.6.1173 .

Baumann, N. (2021). Autotelic personality. In C. Peifer \& S. Engeser (Eds.), Advances in flow research (2nd ed., pp. 231-262). New York: Springer.

Baumann, N., \& Scheffer, D. (2010). Seeing and mastering difficulty: The role of affective change in achievement flow. Cognition \& Emotion, 24(8), 1304-1328. https://doi.org/10.1080/02699930903319911 .

Baumann, N., \& Scheffer, D. (2011). Seeking flow in the achievement domain: The achievement flow motive behind flow experience. Motivation and Emotion, 35(3), 267-284. https://doi.org/10.1007/ s11031-010-9195-4 .

Bowerman, B, L., \& O'Connell, R, T. (1990). Linear statistical models: An applied approach (2nd ed.). Belmont CA: Duxburry Press.
Brunstein, J. C., Schultheiss, O. C., \& Grässmann, R. (1998). Personal goals and emotional well-being: The moderating role of goal dispositions. Journal of Personality and Social Psychology, 75(2), 494 508. https://doi.org/10.1037/0022-3514.75.2.494 .

Carver, C. S., \& Scheier, M. F. (1982). Control theory: A useful conceptual framework for personality-social, clinical, and health psychology. Psychological Bulletin, 92(1), 111-135. https://doi.org/10.1037/ 0033-2909.92.1.111 .

Clarke, S. G., \& Haworth, J. T. (1994). Flow experience in the lives of six-form college students. The British Journal of Psychology, 85(4), 511-523. https://doi.org/10.1111/j.2044-8295.1994.tb02538.x .

Cohen, J., Cohen, P., West, S, G., \& Aiken, L, S. (2003). Applied multiple regression/correlation analysis for the behavioral sciences (3rd ed.). New York: Lawrence Erlbaum Associates.

Csikszentmihalyi, M. (1975). Beyond boredom and anxiety. San Francisco CA: Jossey-Bass.

Csikszentmihalyi, M. (1990). Flow: The psychology of optimal experience. New York: Harper and Row.

Csikszentmihalyi, M. (1997). Creativity: Flow \& the psychology of discovery \& invention. New York: Harper \& Row.

Csikszentmihalyi, M., \& Csikszentmihalyi, I. (1988). Introduction to part IV. In M. Csikszentmihalyi \& I. Csikszentmihalyi (Eds.), Optimal experience. Psychological studies of flow in consciousness (pp. 251-265). Cambridge: Cambridge Univ. Press.

Csikszentmihalyi, M., \& LeFevre, J. (1989). Optimal experience in work and leisure. Journal of Personality and Social Psychology, 56(5), 815-822. https://doi.org/10.1037/0022-3514.56.5.815.

Dawson, J. F. (2014). Moderation in management research: What, why, when, and how. Journal of Business and Psychology, 29(1), 1-19. https://doi.org/10.1007/s10869-013-9308-7 .

Dawson, J. F., \& Richter, A. W. (2006). Probing three-way interactions in moderated multiple regression: Development and application of a slope difference test. Journal of Applied Psychology, 91(4), 917926. https://doi.org/10.1037/0021-9010.91.4.917 .

Engeser, S., \& Rheinberg, F. (2008). Flow, performance and moderators of challenge-skill balance. Motivation and Emotion, 32(3), 158172. https://doi.org/10.1007/s11031-008-9102-4 .

Erhel, S., \& Jamet, E. (2019). Improving instructions in educational computer games: Exploring the relations between goal specificity, flow experience and learning outcomes. Computers in Human Behavior, 91, 106-114. https://doi.org/10.1016/j.chb.2018.09.020 .

Forster, F. (2010). Computerunterstützung von kollaborativen Kreativitätsprozessen. [Computer support in collaborative creativity processes] Saarbrücken: Südwestdeutscher Verlag für Hochschulschriften.

Gable, S. L., Reis, H. T., \& Elliot, A. J. (2003). Evidence for bivariate systems: An empirical test of appetition and aversion across domains. Journal of Research in Personality, 37(5), 349-372. https://doi.org/10.1016/S0092-6566(02)00580-9 .

Hayes, A. F. (2009). Beyond Baron and Kenny: Statistical mediation analysis in the new millennium. Communication Monographs, 76(4), 408-420. https://doi.org/10.1080/03637750903310360 .

Hayes, A, F. (2013). Introduction to mediation, moderation, and conditional process analysis. New York: The Guilford Press.

Hippel, E. von. (2005). Democratizing innovation. Cambridge, MA: MIT Press.

Ilies, R., Wagner, D., Wilson, K., Ceja, L., Johnson, M., DeRue, S., \& Ilgen, D. (2017). Flow at work and basic psychological needs: Effects on well-being. Applied Psychology, 66(1), 3-24. https:// doi.org/10.1111/apps.12075 . 
International Boxing Association. (2012). Katie Taylor: Exclusive interview. Retrieved from http://www.aiba.org/en-US/news/ozqsp/ newsId/4817/news.aspx. Accessed 30 May 2012.

Kanfer, R., \& Ackerman, P. L. (1989). Motivation and cognitive abilities: An integrative/aptitude-treatment interaction approach to skill acquisition. Journal of Applied Psychology, 74(4), 657-690. https:// doi.org/10.1037/0021-9010.74.4.657

Kanfer, R., \& Heggestad, E. D. (1997). Motivational traits and skills: A person-centered approach to work motivation. Research in Organizational Behavior, 19, 1-56.

Kehr, H. M. (2004a). Implicit/explicit motive discrepancies and volitional depletion among managers. Personality and Social Psychology Bulletin, 30(3), 315-327. https://doi.org/10.1177/0146167203256967.

Kehr, H. M. (2004b). Integrating implicit motives, explicit motives and perceived abilities: The compensatory model of work motivation and volition. Academy of Management Review, 29(3), 479-499. https://doi.org/10.2307/20159055.

Kehr, H. M. (2020). Motivation and volition at work. Motivation Science, 6(3), 201-202. https://doi.org/10.1037/mot0000168

Keller, J., \& Bless, H. (2008). Flow and regulatory compatibility: An experimental approach to the flow model of intrinsic motivation. Personality and Social Psychology Bulletin, 34(2), 196-209. https://doi.org/10.1177/0146167207310026 .

Keller, J., \& Blomann, F. (2008). Locus of control and the flow experience: An experimental analysis. European Journal of Personality, 22(7), 589-607. https://doi.org/10.1002/per.692 .

Lakhani, K., \& von Hippel, E. (2003). How open source software works: "Free" user-to-user assistance. Research Policy, 32(6), 923-943. https://doi.org/10.1016/S0048-7333(02)00095-1 .

Langens, T. A., \& Schmalt, H. D. (2002). Emotional consequences of positive daydreaming: The moderating role of fear of failure. Personality and Social Psychology Bulletin, 28(12), 1725-1735. https://doi.org/10.1177/014616702237653 .

Lord, R. G., \& Kernan, M. C. (1987). Scripts as determinants of purposeful behavior in organizations. Academy of Management Review, 12, 265-277.

Marr, A, J. (2001). In the zone: A biobehavioral theory of the flow experience. Athletic insight. The Online Journal of Sport Psychology, 3(1), retrieved from http://www.athleticinsight.com/Vol3Iss1/ Commentary.htm. Accessed 30 May 2012.

Massimini, F., \& Carli, M. (1988). The systematic assessment of flow in daily experience. In M. Csikszentmihalyi \& I. Csikszentmihalyi (Eds.), Optimal experience. Psychological studies of flow in consciousness (pp. 266-287). Cambridge: Cambridge Univ. Press.

McClelland, D. C. (1985). How motives, skills, and values determine what people do. American Psychologist, 40(7), 812-825. https:// doi.org/10.1037/0003-066X.40.7.812 .

McClelland, D, C. (1987). Human motivation. Cambridge: Cambridge Univ. Press.

McClelland, D, C., Atkinson, J, W., Clark, R, A., \& Lowell, E, L. (1953). The achievement motive. Century psychology series. East Norwalk, CT: Appleton-Century-Crofts.

Moneta, G, B. (2012). On the measurement and conceptualization of flow. In S. Engeser (Ed.), Advances in flow research (pp. 23-50). New York: Springer.

Moneta, G. B., \& Csikszentmihalyi, M. (1996). The effect of perceived challenges and skills on the quality of subjective experience. Journal of Personality, 64(2), 275-310. https://doi.org/10.1111/j. 1467-6494.1996.tb00512.x .

Myers, R. (1990). Classical and modern regression with applications (2nd ed.). Boston, MA: Duxbury Press.
Nakamura, J., \& Csikszentmihalyi, M. (2002). The concept of flow. In C. R. Snyder \& S. J. Lopez (Eds.), Handbook of positive psychology (pp. 89-105). Oxford: Oxford University Press.

Pang, J, S. (2010). Content coding methods in implicit motive assessment: Standards of measurement and best practice for the picture story exercise. In Schultheiss O. C. \& J. C. Brunstein (Eds.), Implicit motives (pp. 119-150). New York, NY: Oxford University Press.

Preacher, K. J., \& Hayes, A. F. (2008). Asymptotic and resampling strategies for assessing and comparing indirect effects in multiple mediator models. Behavior Research Methods, 40(3), 879-891. https:// doi.org/10.3758/BRM.40.3.879 .

Rheinberg, F., \& Engeser, S. (2018). Intrinsic motivation and flow. In J. Heckhausen \& H. Heckhausen (Eds.), Motivation and Action (pp. 575-618). Springer.

Roberts, J. A., Hann, I.-H., \& Slaughter, S. A. (2006). Understanding the motivations, participation, and performance of open source software developers: A longitudinal study of the apache projects. Management Science, 52(7), 984-999. https://doi.org/10.1287/ mnsc. 1060.0554 .

Rotter, J. B. (1966). Generalized expectancies for internal versus external control of reinforcement. Psychological Monographs: General and Applied, 80(1), 1-28. https://doi.org/10.1037/h0092976 .

Schank, R., \& Abelson, R. (1977). Scripts, plans, goals, and understanding. New York: Halsted.

Schattke, K., \& Kehr, H, M. (2009). Motivation zur open innovation [motivation in open innovation]. In A. Zerfass (Ed.), Kommunikation als Erfolgsfaktor im Innovationsmanagement: Strategien im Zeitalter der Open Innovation [communication als success factor in innovation management: Strategies in the age of open innovation (pp. 121-140). Wiesbaden: Gabler.

Schattke, K., Brandstätter, V., Taylor, G., \& Kehr, H. M. (2014). Flow on the rocks: Motive-incentive congruence enhances flow in rock climbing. International Journal of Sport Psychology, 45(6), 603-620.

Schattke, K., Brandstätter, V., Taylor, G., \& Kehr, H. M. (2015). Wahrgenommene Leistungsanreize moderieren den positiven Einfluss von Leistungsmotiv-Kongruenz auf das flow-Erleben beim Hallenklettern [perceived achievement incentives moderate the positive impact of achievement motive congruence on flow experience in indoor wall climbing]. Zeitschrift für Sportpsychologie, 22(1), 20-33. https://doi.org/10.1026/1612-5010/a000134 .

Schiepe-Tiska, A., \& Engeser, S. (2017). Measuring flow at work. In C. Fullagar \& A. Delle Fave (Eds.), Flow at work: Measurement and implications (pp. 28-49). Psychology Press UK. https://doi.org/10. 4324/9781315871585-2.

Schiepe-Tiska, A., \& Engeser, S. (2021). Flow in nonachievement situations. In C. Peifer \& S. Engeser (Ed.), Advances in flow research (2nd ed., pp. 109-136). New York: Springer.

Schroer, J., \& Hertel, G. (2009). Voluntary engagement in an open web-based encyclopedia: Wikipedians and why they do it. Media Psychology, 12(1), 96-120. https://doi.org/10.1080/15213260802669466 .

Schüler, J. (2007). Arousal of flow experience in a learning setting and its effects on exam performance and affect. Zeitschrift für Pädagogische Psychologie, 21(3), 217-227. https://doi.org/10. 1024/1010-0652.21.3.217.

Schüler, J. (2010). Achievement incentives determine the effects of achievement-motive incongruence on flow experience. Motivation and Emotion, 34(1), 2-14. https://doi.org/10.1007/s11031-009-9150-4

Schüler, J., \& Nakamura, J. (2013). Does flow experience lead to risk? How and for whom? Applied Psychology: Health and Well-Being, 5(3), 311-331. https://doi.org/10.1111/aphw.12012 . 
Schüler, J., Brandstätter, V., Wegner, M., \& Baumann, N. (2015). Testing the convergent and discriminant validity of three implicit motive measures: PSE, OMT, and MMG. Motivation and Emotion, 39(6), 839-857. https://doi.org/10.1007/s11031-015-9502-1 .

Schultheiss, O, C., \& Brunstein, J, C. (2005). An implicit motive perspective on competence. In A. J. Elliot \& C. Dweck (Eds.), Handbook of competence and motivation (pp. 31-51). New York: Guilford.

Shernoff, D. J., Csikszentmihalyi, M., Schneider, B., \& Shernoff, E. S. (2003). Student engagement in high school classrooms from the perspective of flow theory. School Psychology Quarterly, 18(2), 158-176. https://doi.org/10.1521/scpq.18.2.158.21860 .

Sokolowski, K., Schmalt, H. D., Langens, T. A., \& Puca, R. M. (2000). Assessing achievement, affiliation, and power motives all at once:
The multi-motive grid (MMG). Journal of Personality Assessment, 74(1), 126-145. https://doi.org/10.1207/S15327752JPA740109 .

Thielgen, M. M., Krumm, S., Rauschenbach, C., \& Hertel, G. (2015). Older but wiser: Age moderates congruency effects between implicit and explicit motives on job satisfaction. Motivation and Emotion, 39(2), 182-200. https://doi.org/10.1007/s11031-014-9448-8 .

Winter, D. G. (1973). The power motive. Cambridge, MA: Free Press.

Publisher's Note Springer Nature remains neutral with regard to jurisdictional claims in published maps and institutional affiliations. 